\title{
Famílias monoparentais femininas: um estudo sobre a motivação de mulheres que adotam
}

\author{
Lidia Levy \\ Terezinha Féres-Carneiro \\ Pontifícia Universidade Católica do Rio de Janeiro
}

\begin{abstract}
Resumo
O objetivo deste trabalho é estudar a motivação de mulheres solteiras, viúvas ou divorciadas que procuram a $1^{\text {a }}$ Vara da Infância e da Juventude do Rio de Janeiro com a intenção de adotar uma criança. Através de seus discursos, duas categorias foram destacadas: o desejo de ser mãe e o medo da solidão. Encontramos diferenças entre mulheres que haviam feito outros investimentos na vida que não apenas a maternidade e mulheres para quem a criança pretendida viria dar sentido a uma vida vazia de estímulos e pobre em relações afetivas.

Palavras-chave: adoção; motivação; famílias monoparentais.
\end{abstract}

\begin{abstract}
Monoparental female families: a study about the motivation in women that adopt

The objective of this work is to study the motivation of single, widowed or divorced women who seek the " 1 st Childhood and Family Court of Rio de Janeiro" with the intention of adopting a child. Through their discourses, two categories stood out: the desire to be a mother and the fear of loneliness. We found differences between women who had made other investments in life besides maternity and women for whom the intended child would give meaning to a life empty of stimuli and poor in personal relationships.

Keywords: adoption; motivation; single-parent families.
\end{abstract}

Apesar de a mídia veicular, cada vez mais, notícias sobre o tema da adoção e campanhas serem lançadas, a curiosidade e a estranheza da comunidade persistem. Os Grupos de Apoio à Adoção formados no Brasil ressaltam a necessidade de rever os modelos de família existentes, enfatizando que a criança adotiva não encontra, na maior parte dos livros, um modelo de família como a sua: família composta só de filhos adotivos, de filhos biológicos e adotivos, mãe ou pai solteiro e seus filhos adotivos, entre outras variedades possíveis.

Nos últimos anos, o perfil dos candidatos à adoção vem se modificando em nosso país. O Estatuto da Criança e do Adolescente, em vigor a partir de 1990, estabelece no capítulo III, art. 42, que maiores de 21 anos podem adotar, independentemente de estado civil. Como reflexo das transformações sociais, que produziram novas formas de família, a legislação reconheceu o direito de adoção a pessoas solteiras. Desde então, tem aumentado o número de requerentes solteiros em processos de habilitação para adoção, sobretudo de mulheres.
Féres-Carneiro (1999), ao estudar a demanda clínica de famílias monoparentais, afirma que, na sua grande maioria, essas famílias são constituídas por mulheres com seus filhos. Se considerarmos o número de pessoas solteiras, viúvas ou divorciadas, que procuram a $1^{\text {a }}$ Vara da Infância e da Juventude do Rio de Janeiro, com a intenção de adotar uma criança, encontramos igualmente uma população majoritariamente feminina. Pretendemos no presente trabalho estudar a motivação destas mulheres.

A exaltação da maternidade, desde o século XIX, fez com que o projeto principal das mulheres se restringisse à constituição de uma família e à maternidade. Ainda persiste, em alguns grupos sociais e no imaginário de muitas mulheres, a idéia de que ser mulher é o mesmo que ser mãe. Ao discutir a dissociação feminilidade/maternidade, Badinter (1986) afirma que, embora o destino feminino não esteja mais circunscrito à maternidade, o número de mulheres que exclui deliberadamente o desejo de ser mãe de suas vidas representa uma minoria ínfima da população.

Para Belém (2000), entre os mandatos ancestrais que as mulheres brasileiras tiveram que encarnar está 
"o mandato de representar uma Mãe exemplar e protetora dentro do sistema patriarcal que domina as relações familiares no Brasil” (p. 15). Rocha-Coutinho (1997); em pesquisa com mulheres brasileiras que constituíram família no período do pós-guerra, também verifica que "ser mãe" era a grande finalidade do casamento e o sonho maior da mulher. Entretanto, se a mulher que não tinha filhos era considerada incompleta, não tê-los propiciava-lhe uma abertura para o mundo profissional.

Numa mesma linha de raciocínio, Vaitsman (1994) também entende que a maternidade, ao mesmo tempo desejada e perseguida enquanto realização pessoal, restringiu, para muitas mulheres, outros projetos considerados importantes. Para a autora, a década de 50 foi um marco para a geração da nova classe média brasileira. $\mathrm{O}$ estímulo que as mulheres desta geração receberam para estudar foi um canal não só de aquisição de novos valores mas também de mobilidade social. Na época, a subordinação dos projetos extradomésticos ao casamento provocava uma insatisfação emocional nestas mulheres, cuja identidade não se orientava mais exclusivamente pelos papéis de mãe e esposa.

Segundo Rocha-Coutinho (1997), na década de 60, era comum um discurso de repúdio a qualquer forma de dominação masculina sobre as mulheres, situação esta atribuída à maternidade que, portanto, as mulheres deviam evitar. A maternidade passa a ser incluída não mais como um destino inevitável, mas como um projeto a ser ou não realizado. As mulheres começam a se perguntar acerca das condições ideais a partir das quais um filho seria desejado. A independência como situação ideal contrapunha-se à idéia de que a maternidade traz um estado de dependência da mulher diante do homem. Muitas vezes, porém, o desejo de tornar-se mãe, recalcado através do discurso sobre a independência e a realização profissional, aparecia através de uma gravidez inesperada.

Szapiro (1998) investiga a experiência da maternidade solitária, denominada no Brasil de "produção independente", com um grupo de mulheres de classe média carioca, e constata, a partir do discurso das entrevistadas, que a maternidade foi a experiência de maior realização por elas vivida. Em trabalho posterior, Szapiro \& Féres-Carneiro (2002) ressaltam o crescimento, nos anos 60-70, de um questionamento quanto ao lugar da mulher na sociedade moderna, consequiência da adesão a um projeto individualista, que marca esta época. Os recursos contraceptivos que surgiram nos anos sessenta vieram atender à demanda crescente de liberdade da mulher. A maternidade como produção independente leva a pensar que a emergência do desejo de filho exclui o caráter relacional da maternidade. A maternidade moderna passa a ser questão de livre arbítrio, é uma decisão do indivíduo, antes de ser do par.

Enquanto nos casos de "produção independente", os argumentos utilizados costumam ressaltar os aspectos de independência e livre arbítrio (Szapiro \& Féres-Carneiro, 2002), as mulheres que constituem famílias monoparentais através de uma adoção nem sempre apresentam o mesmo discurso. Em alguns casos, o desejo de um filho era justificado com argumentos semelhantes aos utilizados pelas mulheres que planejavam uma "produção independente", porém, em outros, as justificativas apontavam para uma direção inversa: para um desejo de dependência e para o ressentimento diante da ausência de um outro que se ocupasse de sua vida.

A esterilidade, principal motivação dos casais que adotam, é causa de sofrimento. O cônjuge estéril vivencia uma autodesvalorização e terá que fazer um trabalho de luto para lidar com esta ferida ao seu narcisismo (Levy-Alvarenga, 1998). Algumas mulheres, que adotam sozinhas, além de se ressentirem por não terem construído uma relação amorosa que lhes permitisse formar uma família, também sofrem pela impossibilidade de gerar. Verificamos que certas mulheres investem falicamente o filho que pretendem adotar, na tentativa de suprir o que lhes falta e procurando, através da maternidade, recuperar o valor perdido. Suas expectativas em relação à adoção apresentam, portanto, algumas peculiaridades que precisam ser melhor compreendidas.

\section{Estudo de Casos}

Com o objetivo de avaliar o perfil do adotante e suas motivações, bem como de oferecer subsídios para uma melhor preparação daqueles que pretendem formar uma família pela via da adoção, realizamos um trabalho de pesquisa numa parceria da PUC-Rio com a $1^{\text {a }}$ Vara da Infância e da Juventude do Rio de Janeiro. Apresentamos, neste artigo, os resultados referentes à motivação das mulheres que demandaram uma adoção isoladamente.

O projeto de pesquisa como um todo abrange 129 casais e 41 pessoas requerendo isoladamente uma adoção. Este último grupo é constituído por 36 mulheres solteiras (69\%), viúvas (14\%) e divorciadas (17\%), e 5 homens. Consideraremos na análise dos dados a serem apresentados neste trabalho apenas a motivação das mulheres que se candidataram para uma adoção isoladamente, deixando o estudo acerca dos homens que demandam habilitação, para uma próxima etapa.

As mulheres entrevistadas pertencem a diversos segmentos sociais e apresentam diferentes níveis de escolaridade. Foi realizada uma entrevista semi-estruturada com cada requerente, e consultados os proces- 
sos de habilitação, onde constam dados pessoais e o parecer da assistente social.

A partir do discurso das mulheres, duas categorias de análise emergiram: desejo de ser mãe (24 mulheres); medo da solidão (12 mulheres).
Estas categorias foram articuladas a quatro temas que se destacaram nas entrevistas realizadas: 1. Realização profissional; 2. Cuidar e/ou ser cuidada; 3. Casamento com homem mais velho; 4. Ampliar a família.

Tabela 1 - Freqüência do aparecimento dos temas em cada categoria de análise

\begin{tabular}{lcccc}
\hline & $\begin{array}{c}\text { 1 - realização } \\
\text { profissional }\end{array}$ & $\begin{array}{c}\text { 2 - cuidar e/ou } \\
\text { ser cuidada }\end{array}$ & $\begin{array}{c}\text { 3 - casamento com } \\
\text { homem mais velho }\end{array}$ & $\begin{array}{c}\text { 4 - desejo de } \\
\text { ampliar a família }\end{array}$ \\
\cline { 2 - 5 } I - Desejo de ser mãe & 13 & 4 & 1 & 6 \\
$\begin{array}{l}\text { (Faixa etária: de 34 a 48 anos) } \\
\text { II - Medo da solidão }\end{array}$ & 0 & 8 & 3 & 1 \\
(Faixa etária: de 42 a 67 anos) & 0 & & & \\
\hline
\end{tabular}

O desejo de ser mãe e o medo da solidão podem coexistir em algumas das entrevistadas, mas, neste trabalho, as duas categorias foram separadas por um critério de predominância; ou seja, muitas vezes o desejo de ser mãe existia, porém as providências para uma adoção só foram tomadas diante da perspectiva de uma velhice solitária.

\section{Categoria I - Desejo de ser mãe}

\section{I-1 - Desejo de ser mãe e realização profissional (13 mulheres)}

Algumas destas mulheres desejavam constituir uma família desde a juventude, mas o fato de não terem encontrado um companheiro, com o qual pudessem levar adiante seu projeto, levou-as a investirem grande parte de sua energia no trabalho. Alcançaram uma estabilidade profissional, que talvez não fosse sua meta prioritária. O discurso destas mulheres se aproxima dos obtidos nas pesquisas sobre "produção independente". Algumas nem chegam a explicitar o desejo de uma parceria e enfatizam que a decisão só delas depende, enquanto outras, expressam seu ressentimento por não terem podido estabelecer uma relação satisfatória que justificasse uma gravidez.

"Decidi que se não engravidasse até os 35 anos adotaria ou faria inseminação artificial. Trabalho desde cedo, moro sozinha e tenho sucesso na minha profissão. Já aproveitei muito e sei que este é o melhor momento para ser mãe."

"Meu sonho era ser mãe, mas até agora não surgiu relação significativa que justificasse uma gravidez. Como sou estável profissionalmente, posso bancar uma família sozinha."

\begin{abstract}
"Sempre quis ter um filho, mas meu lado conservador dificulta o relacionamento com os homens. Sou professora e gosto do que faço."

"Meu casamento foi uma decepção, depois de um longo namoro e noivado, me separei um ano depois. Meu sonho era ter uma família e fiquei muito machucada na época. Hoje me dedico muito ao trabalho, me vejo solteira e não me preocupo mais com a solidão; não tenho mais necessidade de um homem ao meu lado”.
\end{abstract}

Outras mulheres afirmam claramente a predominância de uma busca de realização profissional, desde a juventude, diante da perspectiva de uma realização no casamento e na maternidade.

"Sinto-me realizada na profissão. Meu pai lutou para me pagar os estudos e queria que eu vencesse na vida. Acho que pareço com ele, e isto talvez dificulte meu relacionamento com os homens. Não queria ser uma mulher dependente como minha mãe, bem pelo contrário, sempre valorizei minha liberdade".

"Até bem recentemente não pensava em ter filhos, só em me realizar profissionalmente. Fui uma criança estudiosa. Depois de uma relação de seis anos, voltei a morar com meus pais e decidi mudar minha vida. Hoje quero ser mãe”.

Devemos considerar que, para algumas mulheres de classes mais baixas, estudar significou distanciar-se e diferenciar-se da pobreza, ultrapassando os limites sociais e culturais da família de origem. Ao chegarem à meia-idade, realizadas na profissão, questionam-se sobre o resgate de uma maternidade que haviam deixado em segundo plano ou rejeitado enquanto possi- 
bilidade. É o momento em que, revendo seus valores, vêm em busca de uma adoção.

Verificamos que $30 \%$ das mulheres deste grupo mantiveram e mantêm relações afetivas com alguma constância, enquanto que $70 \%$ diziam não ter namorado há muito tempo. Quase todas relatam contato intenso com sobrinhos e afilhados, sendo que $80 \%$ moram sozinhas, e apenas $20 \%$ moram com os pais.

É importante ressaltar que a adoção pode apontar para uma afirmação narcísica, quando o filho expressa um desejo fálico, da mesma forma que o pensamento: "Se não vou ter filhos biológicos vou me realizar profissionalmente". A maternidade é uma experiência alteritária por excelência, o que não ocorre quando o desejo de um filho expressa apenas uma necessidade narcísica. Há, portanto, uma grande diferença em ter filhos, a partir de uma identificação com a figura materna ou a partir de uma identificação virilizante.

\section{I-2 - Desejo de ser mãe articulado ao binômio cuidar e/ou ser cuidada (4 mulheres)}

Encontramos quatro mulheres, todas solteiras, morando com seus pais, sendo que três delas nunca haviam pensado em adotar. Realizavam trabalhos voluntários dentro de suas especialidades em creches e orfanatos e acabaram envolvidas afetivamente por uma criança em particular, vindo demandar adoção para esta criança.

"A vida inteira cuidei de meus sobrinhos e dos filhos dos outros, agora quero cuidar do meu próprio. Chegou a minha vez. Faço trabalhos voluntários e me encantei por um menino da instituição, desejo adotá-lo".

"Nunca pensei em adotar. Sou médica e trabalho voluntariamente para uma instituição. Foi quando conheci meu filho e depois de um ano de convivência, cuidando dele, sabia que já era sua mãe".

O trabalho voluntário pode estar indicando um desejo de cuidar, de maternagem, que, no contato com uma criança específica, motivou a demanda de adoção. Estas mulheres não adotariam uma outra criança, mas pretendiam oficializar um vínculo já estabelecido. Observamos, ainda, que nenhuma mulher incluída nesta categoria manifestou o desejo de ser cuidada.

\section{I-3 - Desejo de ser mãe articulado ao casamento com homem mais velho (1 mulher)}

Uma das entrevistadas sempre desejou um filho, mas não obtendo a aprovação por parte do companhei- ro, adiou seu projeto de maternidade. Após a morte daquele, com uma vida profissional ativa, demanda ser habilitada para uma adoção.

\begin{abstract}
"Meu marido era casado quando nos conhecemos. Separou-se alguns anos depois e vivemos juntos por 20 anos. Quando ele ficou doente, meu tempo livre era para cuidar dele. Agora, posso realizar meu sonho. Vou me aposentar e trabalhar em casa, para ter mais tempo para curtir minha filha".
\end{abstract}

Esta mulher poderia ter sido incluída na categoria I-2, no entanto, por um lado, a necessidade de cuidar surgiu em decorrência da doença do marido, não se revelando como uma tendência prévia, como uma primeira motivação. Por outro lado, em relação à filha esperada, prevalece o "curtir" em relação ao "cuidar".

\section{I-4 - Desejo de ampliar a família (6 mulheres)}

As seis mulheres aqui relacionadas já tinham um filho e desejavam ampliar a família. Algumas pretendiam adotar uma criança de sexo diferente ao(s) do(s) filho(s) já existente(s) (4 mulheres), outras já haviam adotado uma criança anteriormente e vinham em busca de uma segunda adoção (2 mulheres).

"Sou desquitada e tenho um filho adolescente. Gosto de casa cheia e acho que tenho condições de educar mais uma criança".

"Sempre sonhei com uma família numerosa. Tenho um filho biológico de oito anos e não vejo chances de um companheiro no momento que queira investir num projeto de família. Sonho com uma filha mulher e a adoção é o único meio de realizá-lo".

"Tenho dois meninos adotivos, agora falta uma menina para completar a família".

Para estas mulheres ou a esterilidade não era uma questão, ou já havia sido elaborada quando da primeira adoção. Não detectamos sofrimento diante de uma impossibilidade, mas o empenho no sentido de realizar um desejo. Existia uma família monoparental já constituída, e a decisão de aumentá-la era compartilhada com os demais integrantes desta.

\section{Categoria II - Medo da solidão}

\section{II-1 - Medo da solidão e realização profissional}


Curiosamente não encontramos mulheres nesta categoria que tivessem um histórico de realização profissional. Percebemos que a maior parte das mulheres incluídas na categoria II, mesmo tendo uma profissão, não relata investimento no que faz ou fez profissionalmente. Além do mais, muitas são aposentadas, estão próximas da aposentadoria ou são pensionistas, ou seja, uma minoria tem vida profissional ativa. A única mulher que relata realização profissional e ao mesmo tempo alega desejar adotar por medo da solidão, foi melhor incluída em outro grupo.

É importante notar que a média de idade das mulheres relacionadas na categoria 1 é de 40 anos, portanto, significativamente menor do que as da categoria II, cuja média de idade é de 52 anos.

\section{II-2 - Medo da solidão, articulado ao binômio cui- dar e/ou ser cuidada (8 mulheres)}

Aqui foram incluídas cinco solteiras, uma viúva e duas divorciadas. Dentre as solteiras, duas moram com mãe idosa de quem cuidam, duas solteiras moravam com os pais até a morte destes, e uma vive sozinha. No caso desta última, atualmente um namorado reside em sua casa. As três restantes vivem sozinhas, porém têm filhos mais velhos e netos, sendo que duas não têm um bom relacionamento com estes e desejam começar tudo de novo. Para algumas o desejo de ser mãe esteve presente por muito tempo, mas confundido com a necessidade de cuidar e/ou de ser cuidada. Todas têm como motivação principal o medo da solidão e todas querem adotar uma menina.

\begin{abstract}
"Moro numa casa grande e fico como morta sem ter com quem falar. Minha filha, que é adotiva, já tem 33 anos, tem sua família e não me visita. Sofro do mal da solidão. Quero um recém-nascido para poder começar tudo de novo".
\end{abstract}

"Tive vários relacionamentos com o objetivo de engravidar; fiz várias inseminações artificiais e nada. Minha vida é vazia de estímulos e não consegui me realizar como mulher. Moro com minha mãe, que precisa de mim, e dois irmãos solteiros que não conseguem casar".

"Sempre quis ser mãe, mas o tempo foi passando e eu tinha que cuidar de meu pai. Agora que ele morreu, estou sozinha, não tenho amigos ou parentes".

"Moro sozinha há onze anos e há quatro tento engravidar, mas não consigo. Só tenho tido namorados com problemas. Este último é alcoólatra, mas já combinei que ele desocuparia a casa quando a criança chegasse”.

"Moro com minha mãe e sou muito apegada aos meus sobrinhos, de quem cuido desde pequenos. Não acredito mais na possibilidade de ter filhos biológicos e quero poder ainda aproveitar da vida, tendo um filho em minha companhia".

A faixa etária destas mulheres, entre 42 e 67 anos, pode indicar, no caso das solteiras, um confronto com a falta de descendência, provocando uma urgência de concretizar o desejo de maternidade. Não mais podendo serem mães biológicas, a adoção é a única possibilidade que lhes resta. Verificamos que algumas mulheres que sempre foram filhas, pensam em ter uma filha para que esta possa cuidar delas. Enquanto os pais eram vivos, ainda havia uma fantasia de se manter na posição de filha, mas a partir da morte daqueles, enfrentam o medo da solidão.

No caso da viúva e das duas mulheres divorciadas, a intenção de "começarem de novo" aponta para o fracasso das relações anteriores e para uma tentativa de compensarem-se, através de uma nova criança, das frustrações que julgam lhes terem sido impostas pelo outro.

A dificuldade de abandonar a ilusão de segurança provoca uma busca incessante de reconhecimento e de amor. O desejo de ser cuidada, que pode ser aproximado do desejo de dependência, revela um estado de carência e infantilismo, diferente do manifestado por algumas mulheres da categoria I, para quem, constituir uma família monoparental é sinal de autonomia e independência.

Um outro ponto a ser destacado é a exigência de um filho do sexo feminino. Levantamos a hipótese de um movimento de retorno a uma relação mãe-filha pré-edípica, que se tenta reconstruir na relação com a filha mulher, na tentativa de anular a diferença. Se fôssemos considerar apenas o argumento, apresentado em alguns discursos, de que um filho proporcionaria um efeito rejuvenescedor, não faria diferença adotar um menino ou uma menina.

\section{II-3 - Medo da solidão e casamento com homem mais velho (3 mulheres)}

Neste grupo temos duas viúvas, que se relacionam com homens mais velhos, ambas com filhos biológicos, e uma mulher solteira, vivendo maritalmente com um senhor idoso e com uma filha adotiva. As mulheres deste grupo e do anterior apresentam muitos pontos de semelhança quando percebemos que, por um 
lado cuidaram ou cuidam de alguém, mas temem pelo futuro quando se perguntam quem delas cuidará.

\begin{abstract}
"Sou viúva há dez anos. Tenho dois filhos homens. O mais velho é casado, e minha nora é ciumenta e não deixa que eu cuide da minha neta. Tenho um relacionamento com um homem de 65 anos que também é viúvo e abandonado pelos filhos. Nos conhecemos na Igreja e ele quer casar. Quero adotar uma menina de até 4 anos, porque a mocidade em casa é uma alegria".
\end{abstract}

"Vivo com um senhor quinze anos mais velho que não aceita bem a adoção e já disse que não pretende se envolver. Minha filha tem a vida dela, e tenho medo de um futuro solitário”.

Voltamos a encontrar depoimentos que responsabilizam os demais pela própria infelicidade e demonstram a expectativa de, através de um filho, recomeçar a viver. É importante notar que, nos grupos I-3 e II-3, os homens mencionados, em sua grande maioria, já haviam sido casados anteriormente, tinham filhos destes relacionamentos e esperavam, nesta nova relação, ser o centro das atenções e cuidados. Não tinham, portanto, disponibilidade interna para se envolverem no projeto de adoção da companheira.

\section{II-4 - Medo da solidão e desejo de ampliar a famí- lia (uma mulher)}

A única mulher aqui incluída poderia igualmente pertencer aos grupos II-2 e II-3, pelo fato de ter um namorado mais velho e cuidar de uma filha adotiva, que desde cedo apresentou sérios problemas neurológicos, sendo até hoje totalmente dependente dela.

"Desejo dar uma irmã para minha filha. Tenho um namorado, mas ele é muito mais velho do que eu e não fico tranqüila quando penso no futuro da minha filha".

O desejo de ampliar a família, portanto, não coincidia com o desejo de um filho, mas com o desejo de proteger a filha já existente.

\section{CONSIDERAÇÕES FINAIS}

Observando os dados obtidos na pesquisa, verificamos que as mulheres incluídas na categoria I trazem com maior frequiência os temas 1 e 4 , enquanto que as da categoria II, os temas 2 e 3.
Apesar de as mulheres da categoria I estarem referidas a uma falta, tanto quanto aquelas da categoria II, investimentos outros demonstram uma maior capacidade de vinculação. As mulheres incluídas nos grupos I-1 e I-4 expressam outros interesses além da criança a ser adotada, quer seja um trabalho, quer seja um outro filho já existente. Algumas delas chegaram à meiaidade realizadas na profissão e, só então, consideraram a possibilidade de resgatar o que haviam abandonado.

Já as mulheres da categoria II estão mais referidas a frustrações, expressando por vezes, carência, por vezes dependência, por vezes insegurança. Descrevem o filho desejado como uma posse fálica e demonstram um desejo de através deles, preencherem um vazio em suas vidas. A criança viria dar sentido a uma vida vazia de estímulos e pobre em relações afetivas. Em alguns destes casos, aquela que sempre foi filha pensa em ter um filho para que dela venha a cuidar, mantendo sua posição de filha. Outras exerceram o papel de mãe com seus pais, na medida em que deles cuidaram por longo tempo. Suas vidas parecem perder o sentido se não podem continuar cuidando de alguém. Outras, ainda, abdicaram da maternidade em função de um casamento, que lhes dava a perspectiva de serem cuidadas. Viúvas ou com o companheiro envelhecido e doente, preocupam-se com o futuro. Algumas tiveram filhos, hoje têm netos, mas se ressentem pelo afastamento destes. Muitas vezes não mantêm uma relação afetiva com filhos, noras ou genros e acreditam que, "tendo novamente uma criança só delas" possam preencher a solidão.

Enquanto as mulheres que se decidem por uma "produção independente" têm em seu discurso a ênfase no "posso" ("Não preciso de uma relação, posso ter um filho sozinha, posso gerar), a maioria das mulheres que constroem uma família monoparental, pela via da adoção, revelam em seu discurso uma ênfase no "não posso" ("Não consegui uma relação satisfatória que me possibilitasse ser mãe e/ou não posso mais gerar").

As mulheres incluídas na categoria I revelam uma modificação no que hoje se entende por "família". São mulheres que afirmam não haver garantias de que uma criança seria mais feliz e equilibrada emocionalmente, vivendo numa família constituída por um pai e uma mãe e que uma família monoparental pode proporcionar referências estáveis e confiáveis tanto quanto uma família tradicional. Algumas pensam em adotar posteriormente um segundo filho, reafirmando o desejo de formar uma família.

Embora este estudo considere a motivação dos adotantes como uma variável relevante no processo de habilitação para a adoção, achamos importante assinalar que há pontos de vista diferentes, divulgados por outros autores sobre esta questão. Weber (1999, 
2001), por exemplo, relata resultados de estudos sobre as motivações adequadas ou inadequadas para a adoção, ressaltando a inexistência de correlação entre a motivação dos adotantes e o sucesso da adoção. A autora enfatiza o valor da vinculação afetiva que se estabelece entre pais e filhos adotivos como uma variável muito mais importante do que a inadequação inicial para a adoção.

É, sem dúvida, imprescindível, para o enriquecimento dos estudos sobre adoção, que os pesquisadores continuem investigando o papel da motivação do adotante e o valor dos vínculos afetivos construídos entre os membros da família adotiva para uma adoção bem sucedida.

Tendo em vista a crescente demanda de adoção por mulheres solteiras, consideramos relevante, também, continuar investigando suas motivações e fantasias, assim como a natureza dos vínculos familiares estabelecidos em famílias adotivas monoparentais.

Encontra-se em andamento a etapa seguinte desta pesquisa, que tem por objetivo avaliar o vínculo estabelecido entre a criança e sua mãe adotiva e as dificuldades surgidas durante a fase de adaptação.

\section{REFERÊNCIAS}

Badinter, E. (1986). L'un et l'autre. Paris: Odile Jacob.

Belém, M. (2000). Mulher no Brasil, nossas marcas e mitos. São Paulo: Escuta.
Féres-Carneiro,T. (1999). Clínica da família e do casal: tendências da demanda contemporânea. Interações: Estudos e Pesquisas em Psicologia, 3(6), 23-32.

Levy-Alvarenga. L. (1998). Adoção: Repercussões no imaginário dos pais. Foco, Revista da SPCRJ, 18(49), 7678.

Rocha-Coutinho, M. L. (1997). A mulher do pós-guerra no Brasil: Vítima ou sujeito social? Em M. I. D’Ávila Neto \& C. A. Garcia (Orgs.), Mulher: Cultura e Subjetividade. Coletâneas da ANPEPP, 1,7 .

Szapiro, A. M. (1998). Percursos do feminino: Um estudo sobre a "produção independente" dos anos sessenta. Tese de doutorado, PUC-RJ.

Szapiro, A. M. \& Féres-Carneiro,T. (2002). Construções do feminino: Um estudo sobre a "produção independente" pós anos sessenta. Psicologia: Reflexão e Crítica, 15(1), 179-188.

Vaitsman, J. (1994). Flexíveis e plurais: Identidade, casamento e família em circunstâncias pós-modernas. Rio de Janeiro: Rocco.

Weber, L. N. D. (1999). Aspectos psicológicos da adoção. Curitiba: Juruá.

Weber, L.N.D. (2001). Pais e filhos por adoção no Brasil: Características, expectativas e sentimentos. Curitiba: Juruá.

\section{Sobre as autoras}

Lidia Levy: Doutora em Psicologia Clínica pela PUC-RJ, Psicanalista, Professora Assistente do Departamento de Psicologia da PUC-RJ. Terezinha Féres-Carneiro: Doutora em Psicologia Clínica pela PUC-SP, Pós-Doutorado em Psicoterapia de Família e Casal pela Sorbonne, Professora Titular do Departamento de Psicologia da PUC-RJ. 